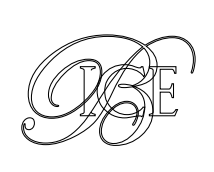

\title{
ASIA MERIDIONAL, UNA REGIÓN EN EXPANSIÓN Breve introducción a su panorama político-económico, con especial referencia a la India
}

Asia Meridional se encuentra actualmente en un ciclo de crecimiento que pone de manifiesto su importancia ascendente. Su población, la más elevada del mundo, la convierte en un mercado repleto de oportunidades, pero graves desigualdades y dispares situaciones políticas advierten de los riesgos también presentes. De entre los países que componen Asia Meridional, por su importancia tanto política como económica, India es el más destacado de estos, y la agenda reformista del Gobierno indio parece indicar un crecimiento sostenido de su economía en los años venideros. Debido a esto, es preciso prestar una mayor atención a su desarrollo y mejorar nuestro conocimiento sobre su realidad. A este objetivo responde este artículo.

Palabras clave: reforma, desigualdad, medio ambiente, crecimiento, población, democracia, integración económica, conflictos regionales, pobreza, sistema bancario, política fiscal, comercio.

Clasificación JEL: O15, O47, Q28, R12.

\section{Introducción}

Si hay una palabra para definir a Asia Meridional, esta sería inmensidad. Inmensidad por su extensión, por tratarse de la región más poblada del planeta, por ser un territorio con una inmensa diversidad cultural, grandes desigualdades y numerosas oportunidades de desarrollo económico. En los últimos años Asia Meridional se ha consolidado como una de las regiones de mayor crecimiento a nivel mundial,

\footnotetext{
*Graduado en Historia e Indi por SOAS, Universidad de Londres. Colaborador-Becario en el Ministerio de Asuntos Exteriores y Cooperación.

Versión de marzo de 2017.
}

y está llamada a tener un mayor peso en el panorama internacional.

Este artículo pretende dar una visión general y de conjunto de Asia Meridional, tratando temas tanto económicos como políticos. Posteriormente se analizará de forma más detallada el caso de la India, al tratarse del país con mayor peso demográfico y económico de la región.

\section{Asia Meridional}

Asia Meridional comprende los Estados de Afganistán, Pakistán, India, Nepal, Bután, $\triangleright$ 
Bangladés y las naciones isleñas de Sri Lanka y Maldivas. Con una población de 1.744 millones y un PIB de 2,69 billones de dólares, Asia Meridional es una región a considerar por su gran importancia económica y estratégica, así como por las posibilidades de desarrollo que presenta, dados su constante crecimiento y la juventud de su población. No obstante, Asia Meridional se enfrenta a enormes desafíos, entre los que destacan las desigualdades sociales, graves conflictos armados y una frágil situación medioambiental.

\subsection{Principales aspectos políticos de Asia Meridional}

Asia Meridional presenta un panorama político complejo. Todos los países de la región son repúblicas, con la excepción de Bután, que se rige por un sistema de monarquía constitucional. La salud democrática de estas repúblicas es diversa. Mientras que la India se puede considerar una democracia estable y funcional, Pakistán, el segundo país de mayor peso en la región, adolece de unas instituciones democráticas débiles, condicionadas por la importancia del ejército, el cual, en gran medida, establece las líneas generales de acción del Gobierno en asuntos de importancia estratégica, como la relación con India. Asimismo, el país ha vivido una serie de golpes de Estado por parte de las fuerzas armadas, el último de los cuales tuvo lugar en 1999 y supuso el control del país por el general Pervez Musharraf hasta 2008.

Por su parte, Nepal, tiene un pasado reciente caracterizado por una guerra civil (1996-2006) entre fuerzas maoístas y el entonces Reino de Nepal. Simultáneamente, las tendencias autocráticas del rey Gyanendra llevaron a una serie de protestas que acabaron con la proclamación de la República Federal de Nepal en 2008. En la actualidad, el país trata de encontrar una estabilidad que, de momento, no llega. Tanto es así que, entre 2008 y 2016, el país ha tenido nueve primeros ministros.

Sri Lanka es un país todavía dividido tras su larga guerra civil (1983-2009), con la minoría tamil reclamando una mejora de su situación y con la coalición gobernante preparando el borrador de una nueva Constitución. La reconciliación entre tamiles y cingaleses y una reducción de la corrupción y del poder de la figura del presidente del país figuran como los grandes objetivos políticos en esta nueva etapa para Sri Lanka.

Tanto Bután como Bangladés mantienen unas estructuras políticas relativamente estables, mientras que en Maldivas las tendencias autocráticas del presidente Abdulla Yameen suponen un grave peligro para la débil democracia, cuya salud, además, no tiene visos de mejorar en un futuro cercano. Tras una sesión del Grupo de Acción Ministerial de la Commonwealth en la que se criticó las tendencias antidemocráticas de Yameen, Maldivas abandonó en octubre de 2016 esta organización.

Entre los problemas que comparten los distintos Estados de Asia Meridional (con la excepción, en la mayoría de casos, del reino de Bután) se pueden señalar como los más destacados el alto porcentaje de pobreza, los conflictos militares internos (como el separatismo baluchi y el terrorismo islámico en Pakistán, guerrillas maoístas en India) o el que se está convirtiendo en quizás el mayor reto al que se enfrenta la región: el cambio climático y el potencialmente devastador impacto que tendría sobre Asia Meridional y su frágil ecosistema. Aparte del riesgo que supone un aumento del nivel del mar sobre las ciudades costeras, los cambios en los sistemas monzónicos y el $\triangleright$ 
incremento de la temperatura supone una amenaza evidente al sector agrícola regional, con las consecuencias sociales, políticas y económicas que esto acarrearía. Sin duda son Bangladés y Maldivas los Estados más amenazados por los cambios en el clima y el aumento del nivel del mar. En el caso de Bangladés, se estima que en torno al 10 por 100 de su territorio se vería sumergido por un aumento del nivel del mar de un metro. Como señala el último informe de The Economist Intelligence Unit, el mayor número de empleos en este país se concentra en el sector agrícola, el cual supone la principal fuente de ingresos para más de la mitad de la población.

Las tensiones existentes entre los distintos Estados de Asia Meridional han supuesto que los proyectos de integración hayan resultado, hasta el momento, generalmente fallidos. La Asociación Sudasiática para la Cooperación Regional (ASACR), el principal organismo de cooperación interregional, fue constituida en 1985. La Unión Europea tiene una relación con esta organización desde la firma de un MoU (siglas en inglés de Memorando de Entendimiento) de cooperación en 1996. Los lazos entre ambas organizaciones se estrecharían en 1999, cuando la UE y la ASACR llegaron a un acuerdo sobre el acceso de productos de Asia Meridional al mercado único, con apoyo técnico europeo para la constitución del Área de Libre Comercio de Asia del Sur, y la armonización de estándares de la ASACR. El desarrollo de las relaciones entre ambos bloques vería la obtención de estatus de miembro observador de la ASACR por parte de la Unión Europea en 2006. No obstante, el camino hacia una mayor integración regional es todavía largo, y, a juzgar por los últimos acontecimientos, no parece que vaya a haber avances en este sentido a corto o medio plazo. El penúltimo recrudecimiento de tensiones entre
Pakistán e India por Cachemira y una amenaza por parte de la India de revisar el acuerdo sobre el uso de las aguas del río Indo culminaron en la negativa del primer ministro indio, Narendra Modi, a atender la última cumbre de la ASACR programada para noviembre de 2016 en Islamabad. Una petición de posposición de la cumbre por parte de Afganistán, Bangladés, Bután e India fue aceptada por Nepal, país que ostentaba la presidencia de la ASACR.

\subsection{Principales aspectos económicos de Asia Meridional}

El desequilibrio económico entre los distintos Estados de la región es uno de los factores más importantes a tener en cuenta. EI PIB combinado de India y Pakistán supone el 90 por 100 del PIB de Asia Meridional. Estos dos Estados mantienen una histórica rivalidad marcada por la disputa por Cachemira, cuatro guerras y numerosos conflictos armados de menor intensidad. A día de hoy se siguen produciendo enfrentamientos con víctimas mortales en ambos bandos, pero una guerra abierta resulta poco probable puesto que ambas naciones son potencias nucleares.

Con India a la cabeza, Asia Meridional supone una excepción al lento crecimiento de la economía internacional. $Y$ no se trata de un fenómeno puntual, sino que, según el Banco Mundial, durante ocho trimestres consecutivos ha sido la región del mundo con un mayor aumento de su PIB. Y es que con la excepción de Afganistán, el resto de países muestran un vigoroso dinamismo.

Esta expansión económica se ha visto impulsada por el consumo interno, tanto público y privado, y por el descenso del precio del crudo registrado en 2016 (dado que todos los $\triangleright$ 
países de la región son importadores netos). Asimismo, Asia Meridional se ha visto poco afectada por la menor demanda de China, ya que su volumen de exportaciones al gigante asiático es relativamente bajo. No obstante, tal y como recoge la publicación bianual del Banco Mundial, South Asia Economic Focus, el aumento del precio del crudo, la caída en el volumen de remesas y unas exportaciones que se mantienen bajas podrían ralentizar el crecimiento de estas economías. El informe de South Asia Economic Focus también señala la necesidad de aumentar la inversión privada que tienen estos países. Cabe señalar que Asia Meridional cuenta con una población joven, desde los 18,6 años de media en Afganistán a los 32,5 de Sri Lanka, y que esto es particularmente reseñable en el caso indio, ya que el crecimiento de su clase media está permitiendo un mayor acceso a la educación superior, con lo que India cuenta con una creciente fuerza laboral cualificada. No obstante, la situación dista mucho de ser ideal; únicamente el 21,1 por 100 de la población entre los 18 y 23 años de edad tiene acceso a la educación superior.

Con la excepción de Maldivas, que muestra una mayor dependencia del sector servicios que el resto de naciones de Asia Meridional, la composición del PIB de los Estados de la región se muestra más equilibrada, con unos porcentajes en el sector agrícola que varían entre el 3,5 en el caso de Maldivas al 29,1 nepalí. En el sector industrial, Nepal muestra el porcentaje más bajo (13) y Bangladés el más elevado, situándose la aportación de la industria al PIB nacional en un 42,1 por 100. Por último, en el sector servicios, Bangladés se sitúa como el país con un porcentaje más bajo, con un 41,5; y Maldivas, con un 77,2 por 100, es el Estado con una mayor participación del sector servicios en la formación del PIB nacional. $\quad \triangleright$
TABLA 1

PIB POR PAÍS

\begin{tabular}{|l|c|}
\hline \multicolumn{1}{|c|}{ País } & PIB en $\mathbf{2 0 1 5}$ (en miles de millones de USD) \\
\hline Afganistán & 19,6 \\
Bangladés & 195,2 \\
Bután & 2,0 \\
India & $2.189,7$ \\
Nepal & 22,4 \\
Pakistán & 271,4 \\
Sri Lanka & 82,3 \\
\hline \multicolumn{2}{|l|}{ Fuente: elaboración propia a partir de datos del Banco Mundial. } \\
\hline
\end{tabular}

TABLA 2

CRECIMIENTO REAL DEL PIB POR PAÍS

\begin{tabular}{|l|c|c|c|c|c|}
\hline $\begin{array}{c}\text { Crecimiento real } \\
\text { del PIB }\end{array}$ & $\mathbf{2 0 1 3}$ & $\mathbf{2 0 1 4}$ & $\mathbf{2 0 1 5}$ & $\mathbf{2 0 1 6 e}$ & $\mathbf{2 0 1 7 e}$ \\
\hline Afganistán & 2,0 & 1,3 & 0,8 & 0,5 & 1,8 \\
Bangladesh & 6,0 & 6,1 & 6,6 & 7,1 & 6,8 \\
Bután & 2,1 & 5,5 & 6,1 & 7,3 & 9,8 \\
India & 6,6 & 7,2 & 7,6 & 7,6 & 7,7 \\
Maldivas & 4,7 & 6,5 & 1,9 & 3,5 & 3,9 \\
Nepal & 4,1 & 6,0 & 2,7 & 0,6 & 5,0 \\
Pakistán & 4,4 & 4,7 & 4,7 & 5,7 & 5,0 \\
Sri Lanka & 3,4 & 4,9 & 4,9 & 4,8 & 5,0 \\
\hline
\end{tabular}

Fuente: elaboración propia a partir de datos del Banco Mundial.

TABLA 3

MEDIA DE EDADY RENTA PER CÁPITA POR PAÍS

\begin{tabular}{|l|c|c|}
\hline \multicolumn{1}{|c|}{ País } & $\begin{array}{c}\text { Media de edad de } \\
\text { la población }\end{array}$ & $\begin{array}{c}\text { Renta per cápita en } \\
\text { 2015 (en USD) }\end{array}$ \\
\hline Afganistán & 18,6 & 601 \\
Bangladés & 26,3 & 1.212 \\
Bután & 27,2 & 2.532 \\
India & 27,6 & 1.674 \\
Maldivas & 27,8 & 7.630 \\
Nepal & 23,6 & 786 \\
Pakistán & 23,4 & 1.437 \\
Sri Lanka & 32,5 & 3.924 \\
Japón & 46,9 & 34.523 \\
China & 37,1 & 8.027 \\
Unión Europea & 42,7 & 32.004 \\
Estados Unidos & 37,9 & 56.115 \\
\hline Fuente: elaboración propia a partir de datos del ClA World \\
Factbook y del Banco Mundial.
\end{tabular}




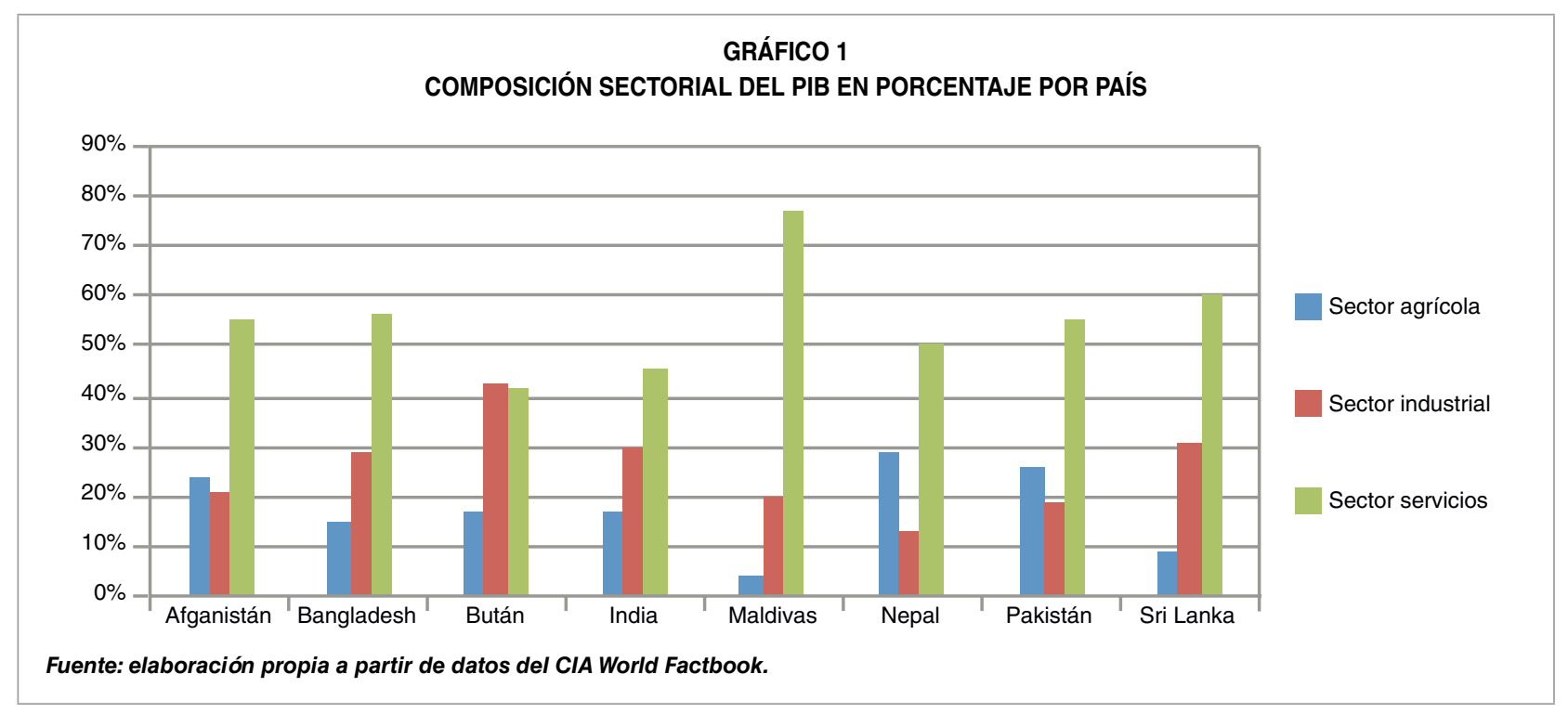

\section{El caso de la India}

La República de la India es un país caracterizado por grandes cifras. Se trata del séptimo país del mundo por PIB y superficie, con sus 3.287.263 kilómetros cuadrados y el segundo más poblado (1.311 millones de habitantes), según las estimaciones más recientes. Además, según previsiones del Departamento de Asuntos Económicos y Sociales de Naciones Unidas, la India superará a China como nación más poblada en 2022.

\subsection{Antecedentes históricos a la India contemporánea}

India conseguiría su independencia de Reino Unido el 15 de agosto de 1947, y en 1950 sería formalmente constituida como república acorde a su Constitución. Antes de exponer su desarrollo histórico como nación, cabe brevemente mentar la importancia del pasado colonial del país. La constitución de un verdadero poder político británico en el subcontinente se suele situar en 1757, cuando la Compañía
Británica de las Indias Orientales se hizo con el control de la provincia de Bengala, región que hoy corresponde aproximadamente a los territorios de Bangladés y de la provincia india de Bengala Occidental. De este modo, una compañía privada se hizo con el control de una de las regiones más ricas de la India, y a partir de ese momento fue paulatinamente aumentando el territorio bajo su control, ya fuera mediante la ocupación directa o mediante el vasallaje de gobernantes regionales. La revuelta de 1857, que hizo peligrar las posesiones británicas en India, llevó al Gobierno británico a hacerse con el control directo de los territorios administrados por esta compañía, debido a la enorme importancia económica que revestía el comercio y las materias primas provenientes de India.

Algunos historiadores indios han querido ver en esta revuelta el nacimiento de un sentimiento nacional. En realidad, varios de los distintos estados indios subyugados por los británicos lucharon de parte del poder colonial, por lo cual este es un argumento débil. No obstante, reclamaciones no atendidas por parte de la corona británica con respecto a los derechos de la población india llevaron a que $\triangle$ 
a principios del siglo xx podamos hablar de un verdadero movimiento independentista, liderado en este caso por el Congreso Nacional Indio.

La ansiada independencia llegaría, pero con ella la partición del territorio en dos Estados: India y Pakistán. Esto se debió principalmente a los miedos de parte de la comunidad musulmana a una dominación por parte de la mayoría hindú y a un agravamiento de las tensiones sectarias en los últimos años de dominio británico. La partición vendría acompañada de una enorme oleada migratoria y de numerosos casos de violencia interreligiosa. Así pues, el nacimiento de la República de la India fue un acontecimiento sumamente traumático. El nuevo Gobierno indio tuvo que enfrentarse a una complicada herencia colonial. Si bien antes de la colonización británica el subcontinente representaba aproximadamente el 25 por $100 \mathrm{del}$ PIB mundial, las nuevas naciones de India y Pakistán eran Estados enormemente empobrecidos, con un tejido industrial mínimo, divisiones sectarias y enfrentados en una guerra entre 1947 y 1949 por el control de Cachemira, región que se vería dividida entre ambos Estados y que se convirtió en una de las principales fuentes de conflicto entre India y Pakistán. De hecho, la disputa por el control de Cachemira continúa siendo a día de hoy uno de los puntos más delicados en las relaciones entre los dos países más importantes de Asia Meridional.

Las primeras décadas de vida de India estuvieron marcadas por el dominio casi absoluto del Partido Indio del Congreso, dominado por la familia Gandhi (no confundir con la figura de Mohandas Gandhi). El primer presidente del Gobierno indio fue Jawaharlal Nehru, que siguió un modelo de planes quinquenales inspirados por los de la Unión Soviética. Durante sus primeras décadas la tasa de crecimiento fue relativamente baja, lo cual solo cambiaría a partir del plan de liberalización de la economía de 1991, liderado por el primer ministro Narasimha Rao y el ministro de Economía Manmohan Singh. Otro acontecimiento de importancia que tuvo lugar durante la década de 1990 fue el crecimiento del llamado nacionalismo hindú, representado políticamente por el Partido Popular Indio (BJP). La coalición liderada por este partido político domina actualmente la Cámara y el primer ministro Narendra Modi pertenece a este partido.

\subsection{Sistema político indio}

El preámbulo de la Constitución India define al país como una república soberana, democrática, socialista y secular. Mientras que la idea de república socialista ha ido perdiendo importancia con el paso del tiempo, el concepto de país secular sigue gozando de una gran importancia, pese a que partidos como el BJP muestran una postura ambivalente con respecto a la inclusión de este término en la definición del Estado. Más allá de cuestiones ideológicas, que el país se defina como una república secular es de una notable trascendencia para las diversas confesiones que la India alberga, teniendo en cuenta los brotes de violencia religiosa y la presencia en el ámbito nacional de un vigoroso nacionalismo hindú. Es importante destacar que la más importante de las minorías religiosas del país, la comunidad musulmana, representa, según el censo realizado en 2011, al 14,2 por 100 de la población, unos 172 millones de personas, lo que convierte a la India en el tercer Estado del mundo con mayor población musulmana.

Sin duda motivada por el tamaño y las grandes diferencias culturales entre sus distintas $D$ 
regiones, la India es una república federal, compuesta por 29 estados y 7 uniones territoriales. El poder legislativo central es bicameral, compuesto por la Lok Sabha (Cámara Baja) y la Rajya Sabha (Cámara Alta). En cuanto a su sistema legal, toma como principales referencias la Constitución de 1950 y el sistema británico de Common Law.

Con respecto al poder ejecutivo, las principales figuras del Estado son el presidente de la República y el primer ministro. El presidente es el jefe de Estado, y, en teoría, el comandante en jefe de las Fuerzas Armadas del país, además de disponer de amplios poderes en materia legislativa, ejecutiva $y$, hasta cierto punto, judicial. No obstante, en realidad, su rol es esencialmente ceremonial, siendo el primer ministro quien realmente hace ejercicio de estos poderes. El presidente de la República es elegido cada cinco años por ambas Cámaras del Parlamento, las Asambleas Legislativas de los 29 estados, y las Asambleas Legislativas de las uniones territoriales de Pondicherry y Delhi, con la posibilidad de reelección para un segundo mandato. El actual presidente de la República es Pranab Mukherjee, del Congreso Nacional Indio. A pesar de que la Constitución fija su rol como similar al de un consejero del presidente de la República, de facto es el primer ministro quien verdaderamente representa el poder ejecutivo del país.

Históricamente el partido político dominante a escala nacional ha sido el Congreso Nacional Indio, liderando el Gobierno del país durante 49 de los casi 70 años de historia de la República de la India. Este partido está íntimamente relacionado con la familia Nehru-Gandhi. Tanto Jawaharlal Nehru como su hija Indira Gandhi, y el hijo de esta, Rajiv Gandhi, han ocupado el cargo de primer ministro de India. La viuda de Rajiv Gandhi es la presidenta del Congreso y su hijo, Rahul Gandhi, participó como candidato del partido en las elecciones de 2014. El Congreso Nacional Indio mantiene como principios fundamentales de su ideario el secularismo y el socialismo. Actualmente este partido se encuentra alejado de su pasada supremacía política, gobernando en seis estados y en la unión territorial de Pondicherry, y controla apenas 44 escaños de la Cámara Baja tras su debacle en las elecciones de 2014.

El otro gran partido indio es el BJP. Fundado en 1980, se convirtió en una de las grandes fuerzas políticas del país a partir de la década de 1990 con el ascenso del nacionalismo hindú. Tras un intento de gobierno fallido en 1996, cuando este partido gobernó durante trece días, en 1998 conseguiría, en alianza con otras fuerzas políticas, hacerse con el Gobierno de la India con Atal Bihari Vajpayee como primer ministro. Este ostentaría el cargo hasta su derrota electoral en 2004, pasando a ser el BJP el principal partido de la oposición. Su contundente victoria en las elecciones de 2014 llevaría a Narendra Modi, ministro jefe del estado de Gujarat, a la oficina de primer ministro. El BJP articula sus posiciones políticas a partir del nacionalismo hindú y una preferencia por un sistema económico neoliberal. EI BJP está íntimamente relacionado con la RSS (siglas en hindi de la Asociación de Voluntarios Nacionales), una controvertida organización en la que numerosos miembros del BJP, incluyendo al actual primer ministro, han militado. La RSS ha sido considerada una organización polémica desde su nacimiento en 1925, y desde la independencia ha sido declarada ilegal en tres ocasiones (1948, 1975-1978, 1992). En esta brevísima introducción al BJP, cabe destacar que a Narendra Modi se le impuso un veto de facto en Estados Unidos y diversas naciones europeas debido a los disturbios de $\triangle$ 
2002 en Gujarat, estado del cual era ministro jefe y en el que la comunidad musulmana fue atacada con gran virulencia, y que ha sido calificada por grupos de académicos y organizaciones humanitarias como un proceso de limpieza étnica. Pese a que el Tribunal Supremo Indio consideró que el Gobierno de Modi no estuvo relacionado de forma alguna con la violencia, son muchas las voces que acusan al actual primer ministro de, en el mejor de los casos, ineptitud a la hora de lidiar con la crisis, o de complicidad con los atacantes.

En un país con una estructura federal, como es el caso de la India, los partidos políticos regionales cuentan con un importante peso a la hora de formular políticas y legislaciones. Esto se ve claramente en la muy frecuente práctica de formación de alianzas entre partidos nacionales y partidos regionales. Varios de estos partidos comparten rasgos como el personalismo de sus líderes y la aparición de verdaderas dinastías políticas.

La India se enfrenta a una serie de desafíos tanto en política interior como en exterior. En política interior, el acomodo de distintos grupos sociales se mantiene como un reto a superar. El ascenso del nacionalismo hindú trae consigo renovadas tensiones en un país en el que los conflictos religiosos y étnicos siempre están latentes. En la India, particularmente en los estados orientales del país, se sigue llevando a cabo una guerra de guerrillas por parte de la insurgencia naxalita, esto es, grupos armados de ideología marxista. A pesar de que su capacidad de acción ha decrecido con los años, su continuada presencia señala que la enorme pobreza y las altas tasas de corrupción presentes en la sociedad india siguen siendo capaces de alimentar un movimiento que lleva en activo desde los años sesenta del siglo pasado.
Política interior y exterior se conjugan en Cachemira como en ninguna otra situación. Este es un enorme problema para la India tanto a nivel de política interior - con una población enormemente descontenta con el poder central- como a nivel de política exterior, debido a a que es una inagotable fuente de tensiones con Pakistán. Tanto es así que India y Pakistán han librado tres guerras por el control de Cachemira, y Pakistán es frecuentemente acusado de colaborar con grupos terroristas islámicos en la región. Además, la población se ve forzada a vivir en un ambiente altamente militarizado, lo que ha llevado a altos niveles de descontento entre la población.

Estas tensiones y la realidad de que, en un conflicto armado convencional, Pakistán sería incapaz de enfrentarse a un, numéricamente muy superior, ejército indio, han llevado a un escenario en el que ambas naciones se han convertido en potencias nucleares, y a un acercamiento por parte de Pakistán a China. $Y$ es aquí donde se presenta el otro gran desafío a nivel de política exterior para la República de la India. La relación entre India y China nunca ha sido especialmente fácil, ya incluso desde los primeros años de independencia india. Estas eran naciones que se podrían considerar aliadas naturales en muchos aspectos; no obstante, la decisión de la India de acoger al Dalai Lama tras la revuelta tibetana de 1959, tensó las relaciones, y en 1962 China e India entrarían en guerra por la región del Aksai Chin. Otro enfrentamiento tendría lugar en 1967 por la posesión del hoy estado indio de Sikkim, y en 1987 se viviría una escalada de tensión entre ambos países por el trazo exacto de las fronteras en el estado indio de Arunachal Pradesh. Pese a que la relación entre India y China ha mejorado notablemente y que actualmente China es $\triangleright$ 
el origen del mayor número de importaciones de la India, existen varios focos de tensión entre ambos Estados. Quizás el más destacado es la cercana alianza de China con Pakistán, y lo que son percibidos por parte de la India como intentos chinos de rodearla con una serie de acuerdos económicos y militares con países limítrofes, como el ya mencionado caso de Pakistán o más recientemente con Sri Lanka.

Esta percepción de riesgo por parte india, así como una mayor sensación de confianza en sí misma, están llevando a la República de la India, especialmente bajo el mandato del actual primer ministro, a llevar a cabo una política exterior muy activa, con acercamientos a Estados Unidos, Japón y otros países del Sudeste Asiático, así como con intentos de mejora de las relaciones con países fronterizos. De este modo, por ejemplo, el año pasado India y Bangladés llegaron a un acuerdo de entrega de tierras para delimitar más claramente las fronteras entre ambos países.

\subsection{Datos básicos de la economía india}

Los principales indicadores macroeconómicos ponen de manifiesto que la República India comienza a establecerse como una de las grandes potencias económicas globales. No obstante, atendiendo a la evolución histórica de la economía y de la sociedad india comparada con aquella de Estados en condiciones de partida similares, podemos ver que el camino hacia una economía plenamente desarrollada es todavía largo. En esto es importante destacar el que es, sin duda alguna, el principal problema al que se enfrenta India: su alto índice de pobreza. Según datos del Banco Mundial, mientras que el PIB indio en paridad de poder adquisitivo (PPA) se sitúa como el cuarto más elevado del mundo, el PIB per cápita se desploma hasta el puesto 122, como consecuencia lógica de la gran desigualdad prevalente en el país asiático. A pesar de la evidente mejora de las condiciones económicas de la población, datos del Banco Mundial registrados en 2011 indican que un 21,2 por 100 de la población del país vive con menos de 1,90 dólares diarios, y 731,9 millones de indios, el 58 por 100 de la población, viven con menos de 3,10 dólares diarios.

\begin{tabular}{|c|c|}
\hline \multicolumn{2}{|c|}{$\begin{array}{c}\text { TABLA } 4 \\
\text { PIB PPA (2015) }\end{array}$} \\
\hline País & PIB PPA (en billones de USD) \\
\hline Brasil & 3,199 \\
\hline China & 19,814 \\
\hline Estados Unidos & 18,037 \\
\hline Federación Rusa & 3,580 \\
\hline India & 7,998 \\
\hline Unión Europea & 19,721 \\
\hline Fuente: elaboración & partir de datos del Banco Mundial. \\
\hline
\end{tabular}

TABLA 5

PIB PER CÁPITA, PPA (2015)

\begin{tabular}{|l|c|}
\hline \multicolumn{1}{|c|}{ País } & PIB per cápita, PPA (USD) \\
\hline Brasil & $15.390,60$ \\
China & $14.450,18$ \\
Estados Unidos & $56.115,72$ \\
Federación Rusa & $24.451,38$ \\
India & $6.100,66$ \\
Unión Europea & $38.702,42$ \\
\hline \multicolumn{2}{|l|}{ Fuente: elaboración propia a partir de datos del Banco Mundial. } \\
\hline
\end{tabular}

A pesar de la crisis mundial iniciada en 2007, la economía india ha sido capaz no solo de mantener unas tasas de aumento de su PIB elevadas, sino también de afianzarse como una de las economías con un crecimiento más vigoroso del panorama internacional. Cabe $\triangleright$ 
comparar el caso indio con el del resto de miembros del grupo de los BRIC. Según datos del Banco Mundial, mientras que la tasa de crecimiento india fue de un 7,2 por 100 en 2014 y un 7,5 por 100 en 2015, China pasó de un 7,2 a un 6,9 por 100 , Rusia cayó de un 0,7 a un $-3,7$ por 100 y Brasil, de un 0,1 por 100 en 2014 a un -3,8 por 100 en 2015.

Son varias las razones que explican este continuado crecimiento de la economía india. En primer lugar, el mercado financiero indio, como es el caso de otros Estados de Asia Meridional, se encuentra poco integrado en el mercado mundial. Lo que se ha podido considerar una desventaja se ha convertido, en un contexto de volatilidad, en una bendición. La caída del precio del petróleo también ha resultado beneficiosa para la India, al ser el tercer mayor importador de petróleo a nivel mundial. Por otra parte, el descenso de la demanda en China tampoco ha supuesto un problema para la economía india debido al bajo volumen de intercambios comerciales entre ambos países. Según datos del Ministerio de Comercio e Industria indio, un 16 por 100 de las importaciones indias provienen de China, mientras que solamente un 3,4 por 100 de las exportaciones indias se dirigen a China. Además, la aceleración de reformas estructurales tras las elecciones de 2014 está permitiendo a la India mejorar sus perspectivas de crecimiento y a mejorar la solidez de su economía de cara a los próximos años.

El crecimiento del PIB indio ha sido impulsado mayoritariamente por el consumo interno, particularmente por el consumo urbano, y por la inversión pública en infraestructuras. Este crecimiento también se ha visto favorecido por unas precipitaciones monzónicas adecuadas que han impulsado al sector agrícola tras unos últimos años duros y un aumento en la remuneración del cuerpo funcionarial. En este sentido, hay que destacar que el actual primer ministro, Narendra Modi, viene de ocupar el cargo de ministro jefe de Gujarat durante trece años (2001-2014), cuya gestión económica se caracterizó por la liberalización de la economía y por la reducción del tamaño y presencia del Estado en la economía. Durante su mandato, el PIB de Gujarat creció a una tasa anual de en torno al 10 por 100, situándolo como uno de los estados indios con mayor crecimiento, gracias al desarrollo de varios proyectos de infraestructura, la expansión de la inversión privada y el rápido crecimiento del sector primario, superior al de cualquier otro estado indio. No obstante, numerosos estudios han argumentado que el desarrollo de Gujarat bajo Modi ha sido similar al de otros estados con condiciones económicas y sociales semejantes; que Gujarat ya experimentaba unas altas tasas de crecimiento durante la década de los noventa, y, la crítica más importante, especialmente en un país como India, que durante su gobierno las desigualdades se agravaron y el desarrollo en educación y sanidad fue claramente insuficiente. No obstante, Modi es considerado por gran parte de la población como un hábil administrador, un gobernante trabajador y un líder claramente opuesto a la corrupción. Lo que es evidente es el claro afán reformista de Narendra Modi, como ha venido demostrando desde su nombramiento como primer ministro en 2014. Sin embargo, reformas con un carácter más políticamente sensible, como son las reformas agraria o laboral, requerirían un consenso político que, tal y como señala The Economist Intelligence Unit, es altamente improbable. Estas acciones solo podrían ser factibles con una mayoría de la coalición liderada por el BJP en ambas Cámaras, lo que al parecer será el caso tras las elecciones de 2019. 
Tras el anuncio por parte del Gobierno de una campaña de desmonetización, las previsiones de crecimiento de la economía india se han revisado ligeramente a la baja. Según el Fondo Monetario Internacional, el aumento del PIB se situará en un 6,6 por 100 para el año fiscal $2016 / 2017$, y en un 7,2 por 100 para 2017/2018.

La inflación ha pasado de una media del 9,8 por 100 , entre 2011 y 2013, a un 4,7 por 100 entre abril y noviembre de este año fiscal, todavía por encima del objetivo del 4 por 100 fijado por el Banco Central Indio. Estimaciones del FMI sitúan la inflación india a medio plazo en valores ligeramente superiores al 4 por 100.

La continuidad de la expansión de la economía india se enfrenta a varios problemas. Además de los asociados a un ritmo de crecimiento elevado, como son el control de la inflación o el desequilibrio de las cuentas exteriores, son especialmente destacados los relacionados con la situación de su sistema bancario y con su política fiscal.

El sistema bancario indio se enfrenta a una serie de desafíos. El más delicado es la caída de los préstamos bancarios a empresas por primera vez en más de dos décadas, y el descenso de las inversiones por parte de estas. Como señala The Economist, esto se debe a que en torno al 16,6 por 100 del valor total del sistema bancario indio se encuentra seriamente comprometido, al tratarse de deudas cuyo pago se considera cuanto menos dudoso. A pesar de que los deudores son principalmente grandes empresas en sectores como infraestructura, minería y telecomunicaciones, la caída en préstamos afecta también a la pequeña y mediana empresa, lo cual es preocupante por su impacto negativo sobre la inversión.

La disminución de la inversión supone dejar al consumo interno como única fuerza de crecimiento de la economía india, ya que la aportación de la demanda externa es negativa, dado que las exportaciones son reducidas e insuficientes para compensar el volumen de importaciones. A día de hoy, el Gobierno se ha comprometido a inyectar más fondos a los bancos, pero por importes muy inferiores a los 90.000 millones que la agencia Fitch considera necesarios. También se ha propuesto la constitución de un «banco malo» para sanear el sistema financiero.

En cuanto a la política fiscal, una de las medidas en materia económica de mayor importancia, emprendidas por el Gobierno de Narendra Modi, ha sido la implantación del impuesto de bienes y servicios (GST). Este nuevo tributo viene a sustituir a varios impuestos sobre el consumo de bienes y servicios nacionales y estatales, y nace con el propósito de simplificar el pago de impuestos, facilitar el desarrollo de un mercado nacional común, eliminar los impuestos en cascada, apoyar la inversión y mejorar la competitividad de la economía india. Los tipos impositivos de este impuesto son del 6 por 100 para productos básicos, del 12 por 100 y del 18 por 100 para la mayoría de operaciones, y del 26 por 100 para productos de lujo. Ciertos productos alimenticios, petróleo, electricidad y bienes inmobiliarios quedan exentos de este impuesto. Su control administrativo se repartirá entre los estados y el Gobierno central, y se espera que entre en vigor a partir de julio de 2017.

Otro de los impuestos que se plantea reformar es el impuesto sobre la renta de las personas físicas. La India adolece de una muy baja capacidad de recaudación por imposición directa; según datos de la OCDE, tan solo 53 millones de indios, lo que equivale a un 5,6 por 100 de su población, pagaron $\triangleright$ 
este impuesto en el año fiscal 2014/2015. Los ingresos por actividades agrícolas se ven exentos del pago de este impuesto, que se aplica a todos aquellos individuos con unos ingresos superiores a dos veces y medio el salario del trabajador medio. El último informe de la OCDE apunta a que la eliminación de desgravaciones fiscales que favorecen a las rentas más elevadas, una incorporación de los ingresos por actividades agrícolas a este impuesto y una expansión de la base fiscal permitirán aumentar la recaudación de este impuesto en un 50 por 100 .

El informe de la OCDE también señala al impuesto sobre sociedades como un gravamen a ser reformado. La tasa impositiva se sitúa en un 30 por 100, reducible a un 23 por 100 en caso de poder acogerse a una serie de beneficios fiscales. Estos beneficios también son, irónicamente, una fuente de problemas para las empresas, al ser el código tributario poco claro y las inspecciones tributarias agresivas. El número de disputas legales relacionadas con este impuesto es elevado, y, de acuerdo a datos obtenidos por la OCDE, alrededor de un 40 por 100 de estas discrepancias acaban en juicios, ocasionando retrasos y contribuyendo a crear un clima de incertidumbre. Para un país que ocupa el puesto 172 de 190 en la lista de Estados en los que el pago de impuestos resulta más sencillo, y para un Gobierno centrado en liberalizar la economía e incentivar el crecimiento empresarial, esto supone un evidente problema. Como respuesta, el Gobierno indio planea una reforma que reduzca la tasa impositiva a un 25 por 100 y que amplíe la base fiscal considerablemente.

Con estas reformas en el ámbito de la política fiscal se pretende aumentar la capacidad de actuación de las Administraciones indias, equilibrar sus cuentas públicas y reducir el endeudamiento público, que es alto en comparación con otras economías emergentes.

La ya mencionada desmonetización ha sido el asunto económico más relevante en la India a lo largo de los últimos meses. El 8 de noviembre de 2016 Narendra Modi anunció, por sorpresa, la retirada de todos los billetes de 500 y 1.000 rupias a efectos inmediatos, y su sustitución por nuevos billetes con una seguridad mejorada. Esto supuso la retirada del 86 por 100 del efectivo en circulación en la India. En un país en el que se estima que alrededor del 40 por 100 de las familias carecen de cuenta bancaria y en el que la economía sumergida representa no menos del 20 por 100 del PIB, esta iniciativa ha supuesto un shock evidente para la población, especialmente para aquella que no vive en los principales centros urbanos, debido a la dependencia del efectivo. El Gobierno ha esgrimido la lucha contra la evasión fiscal como motivo de esta política, pero a corto plazo parece no haber sido especialmente exitosa. El efectivo intervenido proveniente de actividades delictivas ha sido escaso y ha provocado un parón significativo en el consumo interno, el cual, como ya ha sido previamente mencionado, supone la principal fuente de crecimiento del PIB. A medio y largo plazo esta política debería devenir en una reducción de la economía informal. Esta medida ha resultado popular entre una clase baja harta de la corrupción, pero ha cosechado opiniones divergentes en la prensa india y en la prensa especializada internacional, con publicaciones como The Economist criticando duramente a Narendra Modi. Este también ha sido acusado de emplear esta política con resultados puramente partidistas de cara a las elecciones regionales de febrero. 


\section{Conclusión}

Asia Meridional se perfila como una región de grandes oportunidades pero que presenta riesgos y situaciones dispares. Estados como Pakistán o Nepal carecen de la estabilidad necesaria para poder desarrollar su potencial, mientras que la India o Sri Lanka parecen ser suficientemente robustos como para poder gozar de un desarrollo económico y social más vigoroso.

La India afronta problemas asociados a las economías emergentes, como una deficiente regulación fiscal o unas infraestructuras anticuadas, además de dificultades en su sistema financiero que pueden afectar al desarrollo de la inversión. El mayor reto actual al que se enfrenta su economía es mantener las altas tasas de crecimiento sin que se produzcan desequilibrios básicos, y en este sentido el Gobierno parece estar comprometido con un desarrollo sostenible de su economía, adoptando numerosas reformas estructurales. Estas se basan en simplificar la compleja legislación india, facilitar el desarrollo empresarial y mejorar la pobre eficiencia de las Administraciones Públicas. Queda por ver hasta qué punto estas reformas son aplicadas y cuál será su efecto en la economía india y en las condiciones de vida de los habitantes de este país.

Si la India es capaz de solucionar sus problemas estructurales, fomentar el comercio y la inversión privada, mejorar la aún deficiente red de infraestructuras nacional y el nivel educativo y la sanidad nacional, todo hace pensar que pronto se pueda convertir en un verdadero referente a nivel internacional. Por supuesto, y como con tantas cosas, es más fácil decir que hacer. Si bien las principales líneas de actuación en el ámbito político-social del Gobierno indio no siempre coinciden con los valores de la Unión Europea, la orientación de su política económica actual ofrece unas interesantes posibilidades para intensificar las relaciones con la Unión Europea y sus empresas. En todo caso, la India es sin duda alguna uno de los países a los que mayor atención habrá que prestar en los años venideros.

\section{Bibliografía}

[1] ANEEZ, S. (2016). «Divided Maldives parliament backs Commonwealth exit amid ruling party split». Reuters (20 de octubre). Disponible en: http://in.reuters.com/article/ maldives-politics-idINKCN12J2D9

[2] BANCO MUNDIAL (2017). Global Economic Prospects: Weak Investment in Uncertain Times (enero de 2017). Washington D.C. Disponible en: https://openknowledge.worldbank.org/bitstream/handle/10986/25823/9781464810169.pdf

[3] BANCO MUNDIAL (2016). South Asia Economic Focus, Fall 2016: Investment Reality Check. Washington D.C. Disponible en: https: //openknowledge.worldbank.org/bitstream/ handle/10986/25096/9781464809927.pdf? sequence $=2 \&$ is Allowed $=y$

[4] BUNDHUN, R. (2017). «India's damaging reliance on oil». The National (21 de enero). Disponible en: $h$ ttp://www.thenational.ae/business/ economy/indias-damaging-reliance-on-oil

[5] BUNDHUN, R. (2017). «India's trade deficit with China climbs to $\$ 46.56$ billion». The Economic Times (13 de enero). Disponible en: http://economictimes.indiatimes.com/news/ economy/foreign-trade/indias-trade-deficitwith-china-climbs-to-46-56-billion/articleshow $/ 56522187 . \mathrm{cms}$

[6] «BUNDHUN, R. (2017). Talk of a bad bank in India». The Economist (2 de marzo). Disponible en: http://www.economist.com/news/ leaders/21717816-indian-authorities-seemgrasp-threat-wider-economy-ailing-financial

[7] BUNDHUN, R. (2016). "The dire consequences of India's demonetisation initiative». The Economist (3 de diciembre). Disponible en: http://www.economist.com/news/finance-andeconomics/21711035-withdrawing-86-valuecash-circulation-india-was-bad-idea-badly $\quad \triangleright$ 
[8] BUNDHUN, R. (2017). «The high economic costs of India's demonetization». The Economist (7 de enero). Disponible en: http://www.economist. com/news/finance-and-economics/21713842benefits-withdrawing-86-rupees-circulationremain-elusive

[9] FONDO MONETARIO INTERNACIONAL (2017). India 2017 Article IV Consultation (febrero de 2017). Washington D.C. Disponible en: https:// www.imf.org/en/Publications/CR/Issues/2017/ 02/22/India-2017-Article-IV-ConsultationPress-Release-Staff-Report-and-Statementby-the-Executive- 44670

[10] GYAWALI, M. (2014). «The SAARC: A Bloc Whose Time Has Come». The Diplomat (18 oct). Disponibleen:http://thediplomat.com/2014/10/ the-saarc-a-bloc-whose-time-has-come/

[11] OCDE (2017). OECD Economic Surveys: India (febrero de 2017). París. Disponible en: https://www.oecd.org/eco/surveys/INDIA2017-OECD-economic-survey-overview.pdf

[12] PANDA, A. (2017). «Where Do European UnionIndia Relations Stand?». The Diplomat (31 de marzo). Disponible en: $h$ ttp://thediplomat. com/2016/03/where-do-european-union-india-relations-stand/

[13] SAFI, M. (2017). «India's banknote ban: how Modi botched the policy yet kept his political capital». The Guardian (2 de enero). Disponible en: https://www.theguardian.com/world/2017/ jan/02/indias-bank-note-ban-how-modi-botched-the-policy-yet-kept-his-political-capital
[14] SEN, P. (2016). «Modi's Demonetisation Move May Have Permanently Damaged India's Informal Sector». The Wire (16 de noviembre).

[15] SHEPARD,W.(2016). «China's Jewel in the Heart of the Indian Ocean». The Diplomat (9 de mayo). Disponible en: $h$ ttp://thediplomat.com/2016/05/ chinas-jewel-in-the-heart-of-the-indian-ocean/

[16] SHEPARD, W. (2017). «After Day 50:The Results From India's Demonetization Campaign Are In».

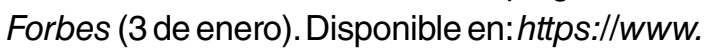
forbes.com/sites/wadeshepard/2017/01/03/ after-day-50-the-results-from-indias-demonetization-campaign-are-in/\#d3e21f550d19

[17] SINGH, A. (2016). «Sri Lanka's Quest for Strategic Prominence in the Indian Ocean. The Diplomat (9 de diciembre). Disponible en: $h t t p: / /$ thediplomat.com/2016/12/sri-lankas-quest-forstrategic-prominence-in-the-indian-ocean/

[18] SINGHAL, R. (2016). «Narendra Modi's currency play has more political value than economic benefit». Quartz India (10 de noviembre). Disponibleen:https://qz.com/833743/narendramodis-currency-play-has-more-political-valuethan-economic-benefit/

[19] WOLF, M. (2017). «India's bold experiment with cash». Financial Times (21 de febrero). Disponible en: https://www.ft.com/content/ e3f2aaa8-f77d-11e6-bd4e-68d53499ed71

[20] WOLF, M. (2017). «India faces another tryst with destiny». Financial Times (28 de febrero). Disponible en: https://www.ft.com/content/ b351b50a-fcec-11e6-8d8e-a5e3738f9ae4 